\title{
The correlation between weight gain and PICC tip shift in the very low birth weight infants
}

\author{
Meng Zhang ${ }^{1 \#}$, Wenyan Yang ${ }^{2 \#}$, Ling Yan ${ }^{2 \#}$, Lizhu Huang ${ }^{1}, \mathrm{Na}$ Lin $^{2}$, Shiyi Zhang ${ }^{2}$, Lilan He \\ ${ }^{1}$ The School of Nursing of Jinan University, Guangzhou, China; ${ }^{2}$ The First Affiliated Hospital of Jinan University, Guangzhou, China \\ Contributions: (I) Conception and design: W Yang, M Zhang, S Zhang; (II) Administrative support: L He, N Lin; (III) Provision of study materials \\ or patients: W Yang, N Lin, L Huang, L Yan; (IV) Collection and assembly of data: W Yang, N Lin, L Huang, L Yan; (V) Data analysis and \\ interpretation: W Yang, M Zhang, L Huang; (VI) Manuscript writing: All authors; (VII) Final approval of manuscript: All authors. \\ "These authors contributed equally to this work. \\ Correspondence to: Lilan He. The First Affiliated Hospital of Jinan University, Guangzhou 510630, China. Email: helilan@yeah.net.
}

Background: Peripherally inserted central catheter (PICC) is one of the important ways to maintain nutrition in premature infants, especially for very low birth weight infants. There are studies have shown that as premature babies grow up after birth, the tip of the PICC will shift away from the heart. When the catheter remove from the central vein, the risk of complications is suddenly increased. Therefore, it is important to predict the position of catheter tip.

Methods: Select the very low birth weight infant (VLBW) infants who used PICC in our hospital from April 2017 to August 2018. And we recorded the birth weight, the weight and the position of the catheter tip of the each filming day, and calculated the rate and speed of weight gain during this period. The correlation was analyzed by the Spearman method.

Results: A total of 49 patients and $151 \mathrm{X}$-rays were enrolled in the study. Of the 49 remaining infants, 40 were in appropriate for gestational age group and 9 were in small for gestational age group. The correlation between weight gain and PICC tip shift in appropriate for gestational ages (AGAs) is statistically significant $(\mathrm{P}<0.05)$. But for SGAs group, the correlation between the rate of weight gain and PICC tip shift was -0.588 $(\mathrm{P}<0.05)$, but there was no correlation between the speed of weight gain and PICC tip shift.

Conclusions: There is a close correction between catheter tip shift and weight gain for those babies. The PICC should be repositioned by X-ray when the rate of weight gain of AGA infants increased to 25\%, 50\%, $70 \%[10 \%, 35 \%, 55 \%$ for small for gestational age (SGA) infants]. For AGAs, when the baby's weight gain speed reaches $1 \%$ and $3.5 \%$, the catheter tip had 2 and 3 vertebral changes, so if the speed of weight gain is excessive faster, we need to increase the frequency of the positioning.

Keywords: Very low birth weight; extremely low birth weight; appropriate for gestational age (AGA); small for gestational age (SGA); peripherally inserted central catheter (PICC); weight gain

Submitted Jan 05, 2020. Accepted for publication Aug 17, 2020.

doi: $10.21037 /$ tp-20-5

View this article at: http://dx.doi.org/10.21037/tp-20-5

\section{Introduction}

Peripherally inserted central catheter (PICC) is one of the important ways to maintain nutrition in premature infants, especially for very low birth weight infants (VLBWs) (1). There are studies have shown that as premature babies grow up after birth, the tip of the PICC will shift away from the heart. When the catheter remove from the central vein, the risk of complications is suddenly increased (2-5). Therefore, it is important to ensure that the catheter tip is in the proper position.

Since secondary catheter ectopic is inevitable (6), we must find a suitable way to measure the catheter position $(5,7)$. The X-ray is still the "gold standard" for determining the tip of the catheter, but frequent exposure to X-rays 
could increases radiation, which is not conducive to catchup growth in premature infants $(8,9)$. But when to position the tip of the catheter again in VLBWs have not yet reached a consensus (10). The purpose of this paper is to explore the correlation between weight gain in premature infants and PICC tip shift, and the right time to determine the catheter tip positioning, to reduce unnecessary complications and provide a safe support for accelerating the catch-up growth of premature infants.

We present the following article in accordance with the STROBE reporting Checklist (available at http://dx.doi. org/10.21037/tp-20-5).

\section{Methods}

\section{Clinical data}

The premature infants hospitalized in our department from April 2017-August 2019 were selected as subjects.

Inclusion criteria:

(I) Born in our hospital and transferred to the NICU within 24 hours.

(II) First tube placement $\leq 2 \mathrm{w}$ after birth and the use time time $>2 \mathrm{w}$.

(III) There are two or more chest X-rays after catheterization.

(IV) PICC catheter tip is clearly visible on the chest.

\section{Study methods}

\section{Data collection}

Recording the general information of the patients, the weight and tip position of the every chest. We use Wn to indicate the weight of babies when they need chest $\mathrm{X}$-ray. For example, $\mathrm{Wt} 1$ is the weight in the first chest day, and Wt2 means the weight of the second chest day. Then, we need calculate the weight gain rate: weight gain rate $=(W \mathrm{tn}$ $-W \mathrm{t} 1) / \mathrm{Wt} 1 \times 100 \%$, and the speed of weight gain $=(\mathrm{Wtn}-$ $\mathrm{Wt} 1) /$ days $\times 100 \%$.

Analyzing the tip of the catheter shifting. We see the first radiography position as a starting point, the change of one vertebral body is recorded as " 1 ". However, if the location has changed, but the change is not enough a vertebral body, we recorded it as " 0.5 ". And if the catheter tip moves away from the heart, we referred it to as “-”, or we will see it as "_"”.

\section{Statistical analysis}

According to the correlation between gestational age and birth weight, the children will be divided into AGA (Appropriate for Gestational Age) group and SGA (Small for Gestational Age) group. All data were analyzed by SPSS 21.0. We expressed the PICC usage time as mean \pm SD. Given a two-sided test with alpha 0.05 , and we compared baseline characteristics of each group with single sample $t$-test. And the correlation relationship analyzed by Spearman.

\section{Ethical statement}

The study was conducted in accordance with the Declaration of Helsinki (as revised in 2013). The study was approved by the IRB of the First Affiliated Hospital of Jinan University (KY-2020-019) and individual consent for this retrospective analysis was waived.

\section{Results}

\section{The baseline characteristics of 49 infants}

A total of 69 premature infants, including 57 very low birth weight children with 245 chest X-ray were found. And 49 babies and 151 chest radiographs were left after excluding the following conditions: the chest radiograph was unclear, and the posture of babies was incorrect, for example, adducted arm or distorted body. There are 21 girls $(42.85 \%)$ and 28 boys $(57.14 \%)$ were included on this subject. Of the 49 remaining infants, 40 were in the AGA group and 9 were in the SGA group. Table 1 show the baseline characteristics of the two groups.

\section{AGA group}

A total of 40 babies were enrolled in this group, including 24 boys (60\%) and 16 girls (40\%), 33 very low birth weight infants (VLBWs) and 7 extremely low birth weight infants (ELBWs). And the most commonly punctured vein was basilic vein $(n=31)$, followed by the median cubital vein $(n=6)$ and others. The Effective vertebral body position changes in this group was 113 .

\section{Catheter tip displacement of AGA group ( $n=40)$}

Excluding the chest radiograph taken during the first tube placement, a total of 113 successful chest radiographs were included in the AGA group. The PICC tip displacement from 0 to 7 vertebral bodies. Table 2 shows the frequency of the each change. 
Table 1 Baseline characteristics of the two groups

\begin{tabular}{lcc}
\hline & AGA $(\mathrm{n}=40)$ & SGA $(\mathrm{n}=9)$ \\
\hline Sex (boy/girl) & $24 / 16$ & $4 / 5$ \\
Birth weight (VLBW/ & $33 / 7$ & $5 / 4$ \\
ELBW) & \\
Vein & & \\
Vena basilica & 31 & 5 \\
Median cubital vein & 6 & 2 \\
Head vein & 1 & 1 \\
Superficial temporal & 1 & 1 \\
vein & 1 & 0 \\
Axillary vein & & \\
Gestational age & 11 & 2 \\
$<28$ & 30 & 6 \\
$28-32$ & 0 & 1 \\
$>32$ & $(42.76 \pm 16.89)[14$, & $(43 \pm 15.2)[27,67]$ \\
PICC usage time & & \\
(mean \pm SD) [min, max] & $109]$ & \\
\hline
\end{tabular}

Table 2 Changes in the number of vertebral bodies $(n=113)$

\begin{tabular}{lcc}
\hline $\begin{array}{l}\text { Changes in the number of } \\
\text { vertebral bodies }\end{array}$ & Frequency & Percent \\
\hline-7 & 1 & 0.9 \\
-5 & 5 & 4.4 \\
-4 & 11 & 9.7 \\
-3 & 28 & 24.8 \\
-2 & 17 & 15.1 \\
-1 & 16 & 14.2 \\
0 & 29 & 25.7 \\
1 & 6 & 5.3 \\
Total & 113 & 100.0 \\
\hline
\end{tabular}

Correlation between PICC tip shift and the rate of weight gain in the AGA group

Spearman's rank correlation analysis showed that the correlation between PICC tip shift and weight growth rate of the infants in the AGA group, $\mathrm{r}=-0.603, \mathrm{P}=0.000$, which indicates that they are relevant. The PICC move away from the heart, as the babies get heavier (Figure 1).
Correlation between PICC tip shift and the speed of weight gain in the AGA group

Spearman's rank correlation analysis showed that the correlation between PICC tip shift and the speed of weight growth of the infants in the AGA group, $r=-0.450, \mathrm{P}=0.000$, which indicates that they are relevant. As can be seen from Figure 2, the faster the weight increases, the greater the change in tip position will be (Figure 2).

\section{$S G A$ group}

A total of 9 babies were enrolled in this group, including 4 boys (44.4\%) and 5 girls (55.6\%), 5 very low birth weight infants (VLBW) and 4 extremely low birth weight infants $(\mathrm{ELBW})$. And the most commonly punctured vein was basilic vein $(n=5)$, followed by the median cubital vein $(n=2)$ and others. The Effective vertebral body position changes in this group was 38 .

\section{Catheter tip displacement of SGA group (n=9)}

Excluding the chest $\mathrm{X}$-rays taken in the first tube placement, a total of 38 successful chest X-rays were included in the SGA group. The PICC tip displacement from 0 to 8 vertebral bodies. Table 3 shows the proportion of the each change.

Correlation between PICC tip shift and the rate of weight gain in the SGA group

Spearman's rank correlation analysis showed that the correlation between PICC tip shift and weight growth rate of the infants in the SGA group, $\mathrm{r}=-0.588, \mathrm{P}=0.000$, which indicates that they are relevant. The PICC move away from the heart, as the babies get heavier, but has a different changing characteristics from the AGA group (Figure 3).

Correlation between PICC tip shift and the speed of weight gain in the SGA group

Spearman's rank correlation analysis showed that the correlation between PICC tip shift and the speed of weight growth of the infants in the SGA group, $\mathrm{r}=-0.160, \mathrm{P}=0.338$, which indicates that they are unrelated (Figure 4).

\section{Discussion}

The average usage time of PICC in VLBWs is longer than peripheral intravenous infusion (11). In this subject, the usage time of PICC is $42 \mathrm{~d}$ (AGA group) and $43 \mathrm{~d}$ 


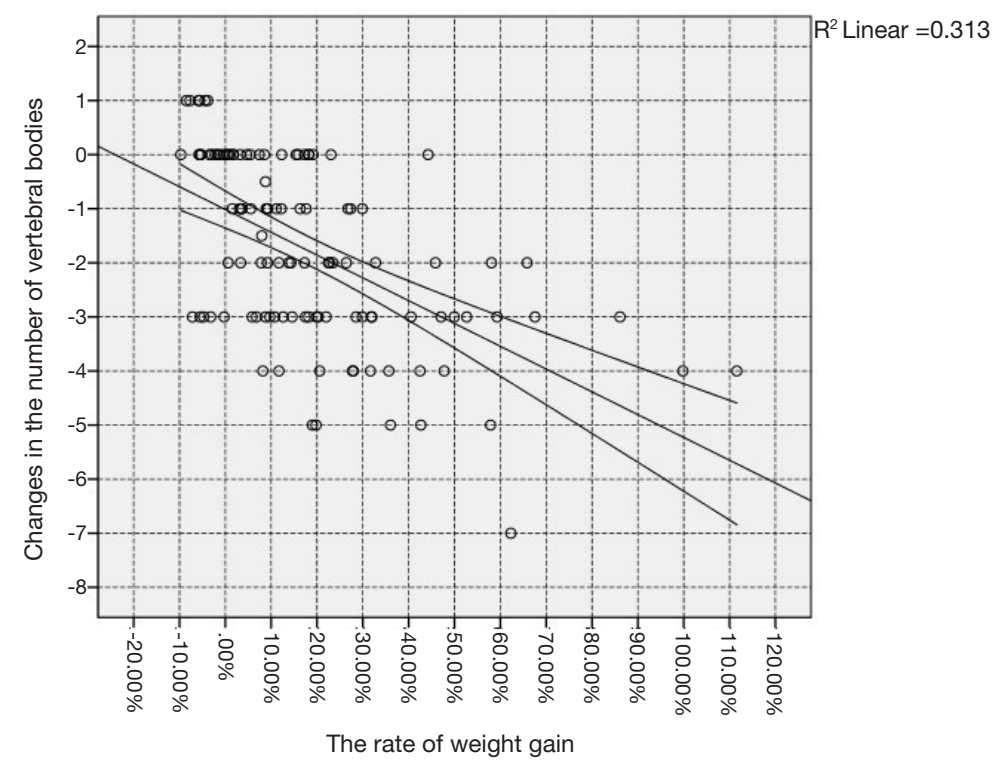

Figure 1 Correlation between PICC tip shift and the rate of weight gain in the AGA group. PICC, peripherally inserted central catheter; AGA, appropriate for gestational age.

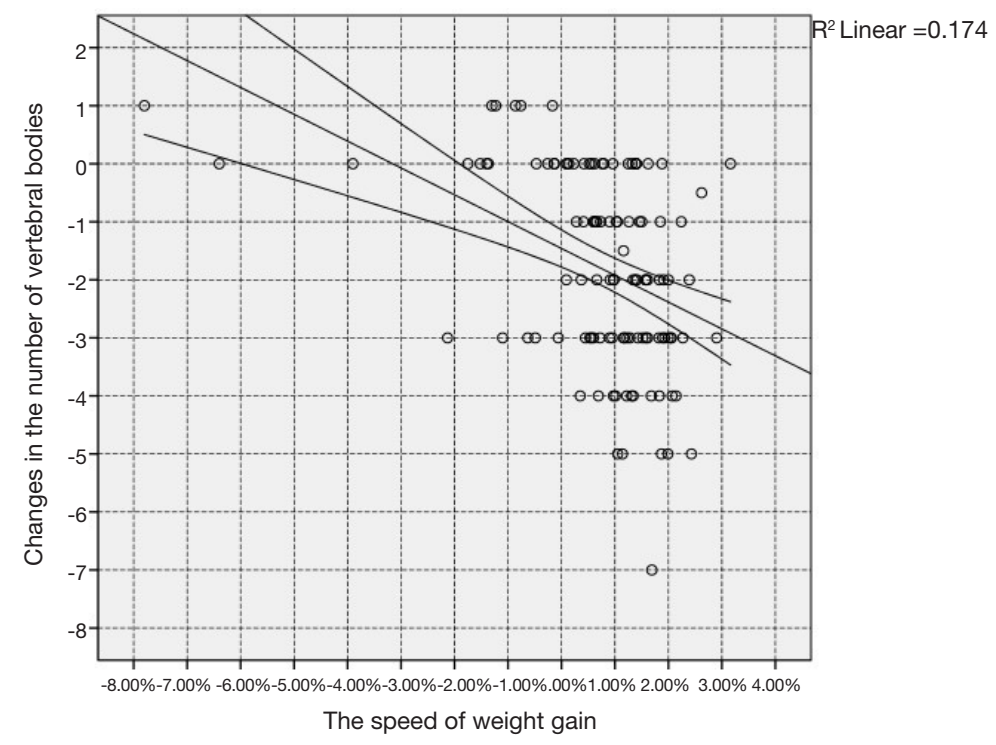

Figure 2 Correlation between PICC tip shift and the speed of weight gain in the AGA group. PICC, peripherally inserted central catheter; AGA, appropriate for gestational age.

(SGA). This study showed that all patients had catheter tip displacement, more than half of the patients had more than 2 vertebral body displacements, and nearly $20 \%$ of the children had more than 5 vertebral body displacements. The position of the PICC tip in VLBWs changes with their weight gain. The catheter tip can be predicted according to the trend of the weight change, and so that the catheter can be repositioned in time to avoid the catheter from coming out of the central vein and reduce unnecessary complications. 
Correlation between PICC tip shift and the rate of weight gain

As can be seen from Figures 1,2, as the child's weight increases, the catheter tip gradually shifts away from the heart (Table 4). Assume that the catheter tip is at the optimal position for the first time, the T6. For AGA infants, the tip of PICC shifts away from the heart about two vertebrae (T4) when the weight increased to $25 \%$, and the catheter tip shifts away from the heart about 4 vertebrae (T2) when

Table 3 Changes in the number of vertebral bodies $(n=38)$

\begin{tabular}{lcc}
\hline $\begin{array}{l}\text { Changes in the number of } \\
\text { vertebral bodies }\end{array}$ & Frequency & Percent \\
\hline-8 & 1 & 2.6 \\
-7 & 1 & 2.6 \\
-6 & 4 & 10.5 \\
-5 & 1 & 2.6 \\
-4 & 5 & 13.2 \\
-3 & 7 & 18.4 \\
-2 & 6 & 15.8 \\
-1 & 10 & 26.3 \\
0 & 3 & 7.9 \\
Total & 38 & 100.0 \\
\hline
\end{tabular}

the weight gain rate is $70 \%$, which has leave away from the central vein. For SGA infants, the tip of PICC shifts away from the heart about two vertebrae (T4) when the weight increased to $10 \%$, and the catheter tip shifts away from the heart about 4 vertebrae (T2) when the weight gain rate is $55 \%$, which has leave away from the central vein. We recommend using this kind of PICC at this time as a peripheral vein or removing it to prevent unnecessary complications. Variation of the catheter tip in the SGA group were faster than AGA group, probably because of gestational age children more apparent from catch-up growth.

\section{Correlation between PICC tip shift and the speed of weight gain}

As can be seen from Figure 3, as the baby grows faster, the catheter tip had more displacement. For AGAs, when the baby's weight gain speed reaches $1 \%$, the catheter tip had two vertebral changes; when it reaches $3.5 \%$, there was about 3 vertebral changes. But the correlation between PICC tip shift and the speed of weight gain of SGAs is not statistically significant $(\mathrm{P}>0.05)$, which may be related to insufficient data (Figure 4).

\section{Limitations of this study}

This study used a retrospective analysis. Not all chest X-ray

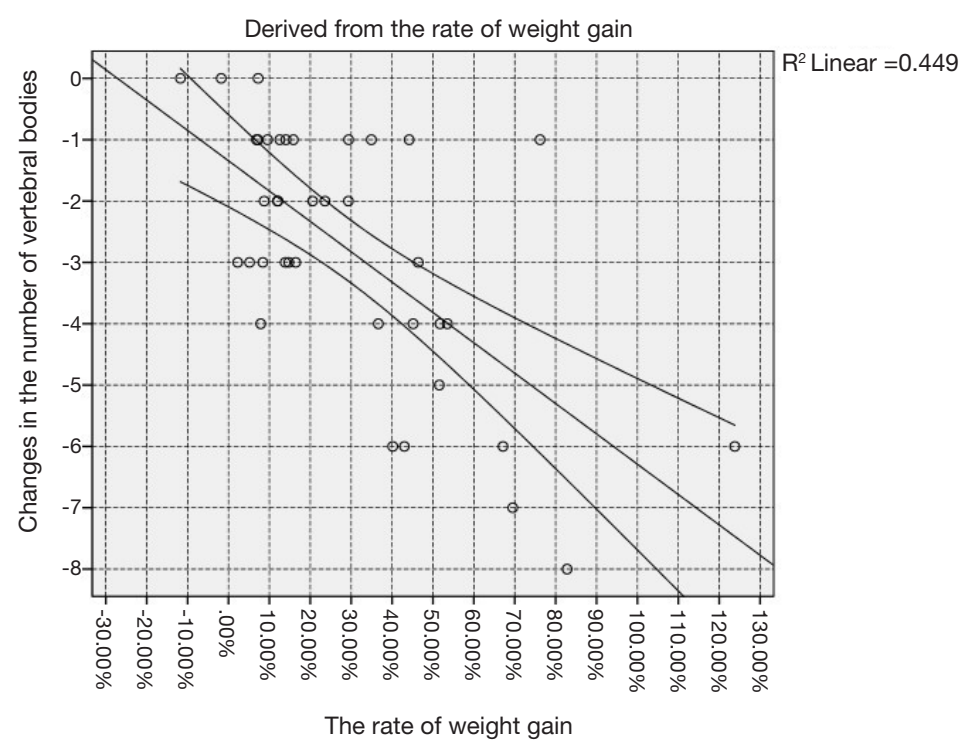

Figure 3 Correlation between PICC tip shift and the rate of weight gain in the SGA group. PICC, peripherally inserted central catheter; AGA, appropriate for gestational age. 


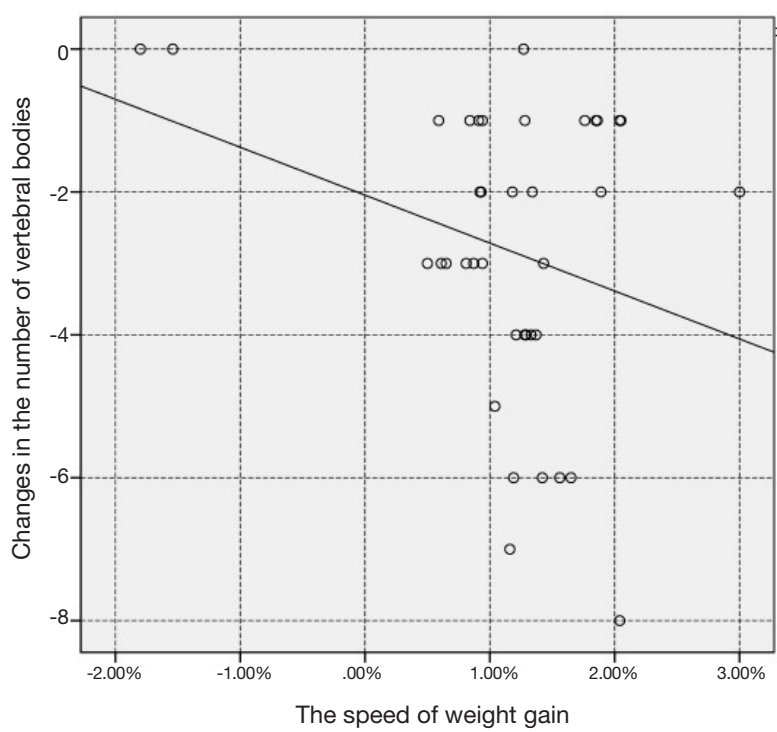

$\mathrm{R}^{2}$ Linear $=0.075$

Figure 4 Correlation between PICC tip shift and the speed of weight gain in the SGA Group. PICC, peripherally inserted central catheter; SGA, small for gestational age.

Table 4 Correlation between PICC tip shift and the rate of weight gain

\begin{tabular}{lll}
\hline $\begin{array}{l}\text { Changes in the number } \\
\text { of vertebral bodies }\end{array}$ & AGA & SGA \\
\hline-2 & $25 \%$ & $10 \%$ \\
-3 & $50 \%$ & $35 \%$ \\
-4 & $70 \%$ & $55 \%$ \\
-5 & $95 \%$ & $75 \%$ \\
-6 & $120 \%$ & $95 \%$
\end{tabular}

AGA, appropriate for gestational age; SGA, small for gestational age.

shoot for catheter positioning, many children did not meet the postural we need, which caused a lot of data loss.

During the study, we found that each child's growth characteristics are different. Some children grow evenly, some children change in height faster than weight while others had the opposite. For children whose weight is changed faster than their height, the shifts in catheter tip is not obvious. But because the hospital does not measure the babies' height routinely, it is difficult to perform analysis.

\section{Conclusions}

In general, VLEW infants have a long time for using PICC, and almost all of them will have catheter displacement due to weight gain. There is a close correction between catheter tip shift and weight gain for those babies. It is clinically possible to predict tip position by measuring the rate of weight gain and calculating the speed of weight gain, to reduce unnecessary radiation damage and complications.

When placing the catheter, nurse should try to ensure that the catheter tip is at the standard position, T6, as an initial and most important method to prevent the catheter leave away from the central vein as the catch-up growth. And during the period of PICC, the daily weight should be recorded, and to predict the position of the tip based on weight gain rate and the speed of weight gain. The PICC should be repositioned by X-ray when the rate of weight gain of AGA infants increased to $25 \%, 50 \%, 70 \%(10 \%$, $35 \%, 55 \%$ for SGA infants), which was consistent with the study of Feixiang L (11). And if necessary, the catheter should be withdrawn. If the speed of weight gain is excessive faster, we need to increase the frequency of the positioning.

\section{Acknowledgments}

First of all, we would like to express my heartfelt thanks to Director Yanzong Song and Director Bingxiao Li of neonatology department of the first affiliated hospital of Jinan University for their strong support to this research. At the same time, we will show our thanks for our friends' 
understanding and support.

Funding: This study has not received financial support from other institutions or individuals.

\section{Footnote}

Reporting Checklist: The authors have completed the STROBE reporting Checklist. Available at http://dx.doi. org/10.21037/tp-20-5

Data Sharing Statement: Available at http://dx.doi. org/10.21037/tp-20-5

Conflicts of Interest: All authors have completed the ICMJE uniform disclosure form (available at http://dx.doi. org/10.21037/tp-20-5). The authors have no conflicts of interest to declare.

Ethical Statement: The authors are accountable for all aspects of the work in ensuring that questions related to the accuracy or integrity of any part of the work are appropriately investigated and resolved. The study was conducted in accordance with the Declaration of Helsinki (as revised in 2013). The study was approved by the IRB of the First Affiliated Hospital of Jinan University (KY-2020-019) and individual consent for this retrospective analysis was waived.

Open Access Statement: This is an Open Access article distributed in accordance with the Creative Commons Attribution-NonCommercial-NoDerivs 4.0 International License (CC BY-NC-ND 4.0), which permits the noncommercial replication and distribution of the article with the strict proviso that no changes or edits are made and the original work is properly cited (including links to both the formal publication through the relevant DOI and the license). See: https://creativecommons.org/licenses/by-nc-nd/4.0/.

\section{References}

1. Blackwood BP, Farrow KN, Kim S, et al. Peripherally

Cite this article as: Zhang M, Yang W, Yan L, Huang L, Lin N, Zhang S, He L. The correlation between weight gain and PICC tip shift in the very low birth weight infants. Transl Pediatr 2020;9(5):596-602. doi: 10.21037/tp-20-5
Inserted Central Catheters Complicated by Vascular Erosion in Neonates. JPEN J Parenter Enteral Nutr 2016;40:890-5.

2. Yu X, Yue S, Wang M, et al. Risk Factors Related to Peripherally Inserted Central Venous Catheter Nonselective Removal in Neonates. Biomed Res Int 2018;2018:3769376.

3. van den Berg J, Lööf Åström J, Olofsson J, et al. Peripherally inserted central catheter in extremely preterm infants: Characteristics and influencing factors. J Neonatal Perinatal Med 2017;10:63-70.

4. Bashir RA, Callejas AM, Osiovich HC, et al. Percutaneously Inserted Central Catheter-Related Pleural Effusion in a Level III Neonatal Intensive Care Unit: A 5-Year Review (2008-2012). JPEN J Parenter Enteral Nutr 2017;41:1234-9.

5. Goldwasser B, Baia C, Kim M, et al. Non-central peripherally inserted central catheters in neonatal intensive care: complication rates and longevity of catheters relative to tip position. Pediatr Radiol 2017;47:1676-81.

6. Gnannt R, Connolly BL, Parra DA, et al. Variables decreasing tip movement of peripherally inserted central catheters in pediatric patients. Pediatr Radiol 2016;46:1532-8.

7. Yi M, Zhang X. Multiple factors analysis for abnormal removal of peripherally inserted central catheter in low birth weight infants. Unrsing Practice and Research 2011;8:5-7.

8. Oleti T, Jeeva Sankar M, Thukral A, et al. Does ultrasound guidance for peripherally inserted central catheter (PICC) insertion reduce the incidence of tip malposition? - a randomized trial. J Perinatol 2019;39:95-101.

9. Walker G, Chan RJ, Alexandrou E, et al. Effectiveness of electrocardiographic guidance in CVAD tip placement. $\mathrm{Br}$ J Nurs 2015;24:S4-S12.

10. NURSES (NANN) N. A. O. N. Peripherally Inserted Central Catheters: Guideline for Practice, 3rd edition: National Association of Neonatal Nurses; 2015, p. 9.

11. Luo F, Chen S, Cheng X, et al. A correlation analysis of PICC tip position and weight gaining in very low birth weight infants. Chin J Nurs 2017;52:949-53. 